\title{
Rational Thinking on Establishment and Improvement of the Employment Service System of College Graduates
}

\author{
Jing SONG, Renzhong ZHOU \\ Shenzhen Polytechnic, Shenzhen, China
}

\begin{abstract}
To establish and improve the employment service system of college graduates is not only currently but also in the future the central task and the core work of the state employment system of college graduates. Based on the work practice and the main bodies involved in the employment of graduates, it were put forward in this paper by the author the theoretical framework of the employment service system as well as some problems of specific research which should be paid attention to.
\end{abstract}

KEYWORD: College graduates; employment service system; problems

\section{THEORETICAL CONSTRUCTION OF COLLEGE GRADUATE EMPLOYMENT SERVICE SYSTEM}

As a strong integration of current kinds of employment work, the establishment and improvement of the college graduate employment service system should focus on new situations and new problems in the future employment of graduates, and a comprehensive innovation of the leadership system and operating mechanism is required. It not only needs to innovate the concept and methods of college graduates in employment, but also requires the related researchers to carry out more thorough and systematic study of the system with a scientific attitude and from a more long-term perspective, thus to build an overall theoretical framework of the employment service system of college graduates, providing a theoretical guidance for the practice of graduates work[1]. To establish and improve the service system for employment of college graduates, as a new proposition for researchers on employment of college graduates at all levels, is also an important opportunity for the scientific, thorough, and systematic research on the employment of college graduates..

\subsection{Research under the Background of Graduates' Work Practice}

Six factors should be included in the research on college graduates employment service system: the institutional operating mechanism of employment management, employment guidance for college graduates, the construction and operation of employment information platform and job market for college graduates, the employment assistance to college graduates from needy families, the implementation and management of employment projects, and the innovation and entrepreneurship of college students. The research on operational mechanism of graduate employment management, including macro-management, organization and operation, and policy making by government and universities on employment of college graduates, will promote to improve the graduate employment system featuring "market-orientation, government regulation, school recommendation, and two-way choice of students and employers", thus to ensure the effective implementation of the work of graduate employment; the research on college graduate employment guidance, including courses of career development education and employment guidance, employment guidance teachers, and practical training, will contribute to utilizing the main role of teaching, strengthens college students' vocational awareness, and improves the ability of job hunting; the construction and operation of employment information platform and job market include construction and standardization of the tangible market and intangible market (relying on IT without physical platform for job supply and demand) of employment of college graduates. Its research will enhance the feedback and early warning of college graduate job market and improve the social adaptability of students with higher education. The innovation and entrepreneurship work is an important measure to implement the policy of 
"creating jobs through entrepreneurship" issued on the 17th National Congress of the CPC and an innovative method to solve the employment problem of college students. From the perspective of research, it is a new breakthrough for the research of employment of college graduates and an important part to improve the college graduate employment service system.

\subsection{Research on Main Bodies Involved in Graduate Employment}

Use Subjects of the research on college graduate employment service system should include four aspects of government, society, colleges and universities, and college students. Clear responsibilities of the parties and their goals are an important part of this research. Some problems are regarded as important elements of this research field: how should the government optimize the industrial structure, strengthen government regulation, and improve the employment policies; the responsibilities of the society in aspects like creating the employment environment, the corporate responsibility, perfecting the market system and related measures; the responsibilities and goals of colleges and universities to improve the quality of personnel training, optimize the structure of talent training, and strengthen the employment guidance; and how could college students take the initiative to enter the society from schools[2].

\subsection{The Initial Theoretical Framework of Graduate Employment Service System Research}

Based on the work practice of college graduates and the main bodies involved in the employment, a exploratory theoretical framework of the employment service system was proposed. The improved employment service system should cover the government (including state and provincial government), universities, and the society, including various factors of policy support, organizational insurance, information platform, the job market, career guidance, counseling service, curriculum, team-building, assessment and monitoring, quality feedback, etc. The employment service system at the government level consists of an advanced IT platform, a working platform to provide organizational insurance, and a service platform of public policies; the employment service system at the university level covers graduate employment services platform, graduate employment and career guidance services platform, and the talent demandoriented service platform; and that at the level of society include systems like the college student internship training, social intermediary services, human resources market, and graduate job market[3].
2 PROBLEMS THAT SHOULD BE PAID ATTENTION TO IN ESTABLISHING AND IMPROVING THE COLLEGE GRADUATE EMPLOYMENT SERVICE SYSTEM

\subsection{Grasp the Correct Research Principles}

(1) Adhere to the principle of learning from practice and applying it into the practice

To establish and improve the service system for employment of college graduates is the inevitable requirement during a certain stage of China's economic and social development and the popularization of higher education. The work practice of China's college graduates is the basis of establishing and improving the employment service system of college graduates, and the ultimate purpose of the study is to guide the establishment and improvement of college graduate employment service system. Therefore, the system construction of this study must proceed from reality, emancipate the mind, seek truth from facts, and advance with the times, thus to creatively analyze and interpret problems of establishment and improvement of college graduate employment service system and obtain realistic theoretical generalization.

(2) Adhere to the principle of the combination of self-development and learning from foreign countries

In China, without systematic research on employment of college graduates, there are mainly some spontaneous, sporadic, and non-systematic studies. Therefore, to build a research system of college graduate employment service system, it is required to carefully analyze and summarize the history and current situation of employment of Chinese college graduates to streamline and promote the experience to be the theory which has been integrated and systematized. On the other hand, the successful experience and development theory of the employment of foreign college graduates must be seriously studied and learned from to help overcome our own weaknesses to accelerate the process of building the college graduate employment service system. While combining self-development with the foreign experience, what must be paid special attention to is that learning from the successful experience and mature theories of foreign countries should be based on the reality of China, promoting the "localization" to adapt to China's economic, social, and cultural environment[4].

\subsection{Stick to the Scientific Methods}

A method is a tool to solve problems in research on college graduate employment service system.

(1) Qualitative analysis refers to analyze and process a large amount information obtained from the phenomenon to seek the regular rules. To fully analyze the provisions of the employment of college 
graduates, a lot of social surveys must be conducted based on practice and scientific abstraction to form the theory of college graduate employment service system, which would be tested and perfected in its development and practice. Qualitative analysis method is more suitable for aspects like college graduate employment policy making and interpretation and analysis of employment measures. The quantitative analysis of research on college graduates employment service system features using mathematical measurement or mathematical modeling to study graduate employment phenomenon and the relationship between the employment and socio-economic development in order to discover the rules of employment of college graduates. The use of the quantitative analysis is more scientific and more credible for analyzing the employment of college graduates and the correlation between demand of talents and supply of college graduates. Quantitative analysis method has been frequently used to predict the scale of training talents of various disciplines of higher education.

The qualitative research, based on descriptive analysis, is in essence a process of induction, which means to draw general conclusions from particular phenomena; while quantitative research, with the characteristic of deduction, is studying special phenomena based on a general phenomenon. As for the college graduate employment service system, using only qualitative or quantitative analysis is rare. Qualitative research is the basis of quantitative research, and quantitative research is the prerequisite for the qualitative study. Qualitative research combined with quantitative research is one of the ideal research methods to study college graduate employment service system.

(2)The combination of macro research and micro research

Using the method of macro analysis for the research on college graduate employment service system is a careful investigation of the employment of college graduates from the perspective of economic and social development environment, including the research on mutual relationship between the employment of college graduates and economic policies, legal environment, cultural background, etc. Without a certain social and economic development background, it's difficult to obtain accurate and scientific conclusions from abstract study of employment of college graduates.

Microscopic analysis is mainly used for the analysis of and research on the employment of college graduates in one college or a certain aspect of employment of college graduates. Using microscopic analysis of the employment of college graduates (one aspect of employment) for the analysis and interpretation should follow the order of problem discovered, observation, summary, theory, explanation, and problem solved. Specifically, it means to focus on the problem to observe its activities and deduce the phenomenon to find its inner links, then summarize the rule of the activities according to the inner links and use the rule (theory) to explain the nature of the phenomenon, and finally achieve the ultimate aim, the ideal solution for the problem.

This kind of research line could be utilized in training objectives and talents position of colleges and universities as well as curriculum development of career development and career guidance. In research practice, as two methods which could complement each other, the microscopic analysis should take macro research as the foundation, and the former is also the basis of the latter.

(3) Multidisciplinary combination

Since the employment of college graduates is the closest connection between education and social and economic development. To adapt to society, meet the needs of the society, and serve the society, it is required to examine the employment theory and practice of college graduates with theories and methods of multiple disciplines like sociology, economics, education, psychology, and system science to fully absorb the results of multidisciplinary studies. Only with the deep comparative analysis could obtain new breakthroughs in the study; The construction of college graduate employment service system requests scientifically applying the cross connection among the multiple subjects and learning from the research model of natural sciences, social sciences, and humanities in accordance to the nature and characteristics of the study, adhering to service orientation and problem orientation, thus to build a complete and scientific service system of college graduates' employment. For instance, the introduction of sociological theory of social stratification will better explain the aggregation of professional choice; the introduction of economics will explain the choice of jobs of college graduates from the perspective of human capital investment and income; the introduction of psychology could guide the professional development of college students according to the match of talents and positions; the introduction of pedagogy, returning to education, refers to recognize the importance of professional development education based on the essence of promoting the social characteristic of the educated through education.

\section{REFERENCES}

[1] PAN Maoyuan. The Research Method of Higher Education. Higher Education Press, 2008:20-40 (in Chinese).

[2] LU Xueyi. Research Report of Social Strata in Contemporary China. Social Sciences Academic Press, 2002:56 (in Chinese). 
[3] ZHU Li. Principles of Sociology. Social Sciences Academic Press, 2003: 24 (in Chinese).

[4] CHENG Qi. Research on Chinese College Graduate Employment Service System Based on International
Comparison. Dalian: Dalian University of Technology, 2009 (in Chinese). 